\title{
The Epithelial-Mesenchymal Interaction Plays a Role in the Maintenance of the Stem Cell Niche of Mouse Incisors via Fgf10 and Fgf9 Signaling
}

\author{
Tamaki Yokohama-Tamaki ${ }^{1}$, Naoki Fujiwara ${ }^{2}$, Shunichi Shibata ${ }^{1}$, Satoshi Wakisaka ${ }^{3}$ and \\ Hidemitsu Harada ${ }^{2, *}$
}

\author{
${ }^{I}$ Division of Histology, Department of Oral Growth and Development, School of Dentistry, Health Sciences University \\ of Hokkaido, Hokkaido, Japan; ${ }^{2}$ Department of Oral Anatomy II, School of Dentistry, Iwate Medical University, Iwate, \\ Japan and ${ }^{3}$ Department of Oral Anatomy and Developmental Biology, Graduate School of Dentistry, Osaka University, \\ Osaka, Japan
}

\begin{abstract}
The continuous eruption of mouse incisors throughout life is maintained by adult stem cells in the apical end. In these teeth, the continuous expression of Fgf10 in the mesenchyme plays a role in the maintenance of the epithelial stem cell compartment, referred to as the "apical bud." However, little is known about the epithelial signaling that induces and maintains FgflO expression. Focusing on the epithelial-mesenchymal interaction during tooth development, we thoroughly investigated candidates expressed in the apical bud. In situ hybridization and immunostaining showed that Fgf 9 mRNA and protein were detected in the basal epithelium, stellate reticulum, and inner enamel epithelium of the apical bud. Recombinant Fgf9 protein stimulated cell proliferation in cultures of apical end mesenchyme. Furthermore, Fgf9releasing beads inhibited apoptosis in mesenchymal tissue cultures and maintained the expression of $F g f 10$. On the other hand, Fgf10-releasing beads induced Fgf9 expression in cultures of apical buds. Taken together, these results suggest that the stem cell niche in growing incisors is maintained by an epithelial mesenchymal interaction via Fgf9 and Fgf10 signaling.
\end{abstract}

\section{INTRODUCTION}

Mouse incisors are continuously growing teeth that are maintained by both cell proliferation at the apical end and attrition of the incisal edge. This type of tooth has a special epithelial bulge structure referred to as an "apical bud," which maintains epithelial adult stem cells [1]. The apical bud consists of a large stellate reticulum (SR) which contains the stem cells, the basal epithelium (BE), the inner enamel epithelium (IEE), and the outer enamel epithelium (OEE). The stem cells divide slowly, giving rise to one daughter cell that remains in the SR and another cell that enters the zone of rapidly dividing IEE cells (the transit-amplifying cell population) to differentiate into ameloblasts that deposit the enamel matrix.

The processes of tooth development are regulated by the sequential and reciprocal interactions between the oral ectoderm and the neural crest-derived mesenchyme [2]. Several signaling pathways and transcription factors have been implicated in regulating molar crown development, but relatively little is known about the regulatory mechanisms of continuous incisor growth. We previously reported, using Fgf10-deficient mice, that Fgf10 maintains the epithelial stem cell compartments of mouse incisors [3]. However, the regulation of Fgf10 signaling has not been studied sufficiently in tooth development. Based on the epithelialmesenchymal interactions during tooth development, the mesenchymal stem cells seem to rely upon epithelial cues for

*Address correspondence to this author at the Department of Oral Anatomy II, School of Dentistry, Iwate Medical University, Iwate, Japan 020-8505, Japan; Tel: +81-19-651-5111; Fax: +81-19-652-4652;

E-mail: hideha@iwate-med.ac.jp their survival and differentiation [4, 5]. Fibroblast growth factors (Fgfs) play a critical role in developing teeth [6,7]. In this study, which was intended to elucidate the mechanism for the continuous growth of mouse incisors, we searched for growth factors maintaining $\mathrm{FgflO}$ expression by epithelialmesenchymal interactions. We report a candidate molecule, Fgf9.

\section{MATERIALS AND METHODS}

\section{RT-PCR Analysis}

Mandibular incisors were carefully microdissected from neonatal, 1-day-old mice. Tissues were immediately suspended in RNAlater RNA Stabilization Reagent (QIAGEN), and total RNA was extracted using an RNeasy Micro Kit (QIAGEN). After cDNA synthesis using oligo (dT) primers and reverse transcriptase, RT-PCR analysis was performed using the primer sets shown in Table 1. Amplification products were analyzed on $2.0 \%$ agarose gels and visualized by staining with ethidium bromide.

\section{Immunohistochemistry}

Mandibulars of neonatal 1-day-old mice were dissected, fixed overnight in $4 \%$ paraformaldehyde, dehydrated, and embedded in paraffin. Serial $10-\mu \mathrm{m}$ sections were taken in the sagittal plane. Antigens on the paraffin sections were activated in citric buffer at $121^{\circ} \mathrm{C}$ for $10 \mathrm{~min}$. Rabbit antiFgf9 polyclonal antibody was used as the primary antibody $(0.5 \mu \mathrm{g} / \mathrm{ml})$ (CHEMICON, USA). Detection was carried out using a VECTASTAIN Elite ABC KIT (Vector, USA) and a DAB kit (Vector, USA) for color reactions according to the manufacturers' instructions. The sections were counterstained by hematoxylin. 
Table 1. Primer Sets for RT-PCR

\begin{tabular}{|c|c|c|}
\hline cDNA & Sequence $\left(5^{\prime} \rightarrow 3^{\prime}\right)$ & Size \\
\hline$F g f l$ & $\begin{array}{l}\text { Forward: ACCGAGAGGTTCAACCTGCC } \\
\text { Reverse:GCCATAGTGAGTCCGAGGACC }\end{array}$ & $387 \mathrm{bp}$ \\
\hline$F g f 2$ & $\begin{array}{l}\text { Forward: AGCGGCATCACCTCGCTTCC } \\
\text { Reverse:TGGAAGAAACAGTATGGCCTTCTGTCC }\end{array}$ & $438 \mathrm{bp}$ \\
\hline$F g f 3$ & $\begin{array}{l}\text { Forward:GATGGGCCTGATCTGGCTTCTGCT } \\
\text { Reverse:CACCATCTCATGGTCCTTGTGGCC }\end{array}$ & $573 \mathrm{bp}$ \\
\hline Fgf4 & $\begin{array}{l}\text { Forward:ACCACAGGGACGCTGCTGCCCA } \\
\text { Reverse:CCTTCATGGTAGGCGACACTCGGT }\end{array}$ & $567 \mathrm{bp}$ \\
\hline Fgf5 & $\begin{array}{l}\text { Forward:CATCTTCTGCAGCCACCTGATCCA } \\
\text { Reverse:AAGTTCCGGTTGCTCGGACTGCTT }\end{array}$ & $652 \mathrm{bp}$ \\
\hline Fgf6 & $\begin{array}{l}\text { Forward:CACGCTGCAGGCTCTCGTCTTCTT } \\
\text { Reverse:CAGTCATGATTGGGGACACCTTGC }\end{array}$ & $542 \mathrm{bp}$ \\
\hline Fgf7 & $\begin{array}{l}\text { Forward:CAATCTACAATTCACAGA } \\
\text { Reverse: AGCCCCTTTTGATTTAAG }\end{array}$ & $622 b p$ \\
\hline Fgf8 & $\begin{array}{l}\text { Forward:CTGAGCTGCCTGCTGTTGCACTTG } \\
\text { Reverse:GGTAGTTGAGGACTCGAAGCGCA }\end{array}$ & $568 \mathrm{bp}$ \\
\hline$F g f 9$ & $\begin{array}{l}\text { Forward:ATGGCTCCCTTAGGTGAAGTTGG } \\
\text { Reverse:GCCTCCGCCTGAGAATCCCCTTTAAATG }\end{array}$ & $196 \mathrm{bp}$ \\
\hline Fgflo & $\begin{array}{l}\text { Forward:TCACCTGCCAACTCTTGGT } \\
\text { Reverse:CCGTTCTTCTCAATCGTGAG }\end{array}$ & $190 \mathrm{bp}$ \\
\hline Fgfrlb & $\begin{array}{l}\text { Forward:GGGCAGCAATGTGGAGTTCA } \\
\text { Reverse:TTGCCACAGGTCTGGTGACA }\end{array}$ & $278 \mathrm{bp}$ \\
\hline Fgfrlc & $\begin{array}{l}\text { Forward:GGGCAGCAATGTGGAGTTCA } \\
\text { Reverse:GTGATGGGAGAGTCCGATAG }\end{array}$ & $250 \mathrm{bp}$ \\
\hline$F g f r 2 b$ & $\begin{array}{l}\text { Forward:GGAGGGGATGTGGAGTTTGT } \\
\text { Reverse:ACTGGTTGGCCTGCCCTATA }\end{array}$ & $244 \mathrm{bp}$ \\
\hline$F g f r 2 c$ & $\begin{array}{l}\text { Forward:GGAGGGGATGTGGAGTTTGT } \\
\text { Reverse:CAGAACTGTCAACCATGCA }\end{array}$ & $271 \mathrm{bp}$ \\
\hline$F g f r 3 b$ & $\begin{array}{l}\text { Forward:TCAGTGAGAATGTGGAGGCA } \\
\text { Reverse:TGCCAGCCTCATCAGTTTCC }\end{array}$ & $180 \mathrm{bp}$ \\
\hline$F g f r 3 c$ & $\begin{array}{l}\text { Forward:TAACACCACCGACAAGGAGA } \\
\text { Reverse:TGCCAGCCTCATCAGTTTCC }\end{array}$ & $170 \mathrm{bp}$ \\
\hline Fgfr 4 & $\begin{array}{l}\text { Forward:CGTGGTCGTCACTGGTACAA } \\
\text { Reverse:TGATGGAGGTTAAGGAGTC }\end{array}$ & $190 \mathrm{bp}$ \\
\hline CMHPRT & $\begin{array}{l}\text { Forward:GCRTCGTGATTRGCGATGATGA } \\
\text { Reverse:GTCRAGGGCRTATCCAACAACA }\end{array}$ & $562 \mathrm{bp}$ \\
\hline
\end{tabular}

\section{Cell Proliferation Assay}

Primary dental mesenchymal cells were dissected from lower incisor germs. These cells were treated with trypsin and dispase. A total of $0.5 \times 10^{4}$ cells per well were inoculated onto 96-well plates containing $100 \mu \mathrm{l}$ of medium $(\alpha$-MEM, $10 \%$ FBS) per well, and recombinant human Fgf9 protein (CHEMICON, USA) was added to the medium at various concentrations ( $0 \mathrm{ng} / \mathrm{mL}, 1 \mathrm{ng} / \mathrm{mL}, 10 \mathrm{ng} / \mathrm{mL}$, or $100 \mathrm{ng} / \mathrm{mL}$ ). The cells were counted in 7 days. Points represent means \pm SEM of three replicates.

\section{Recombinant Proteins and Treatment of Beads}

To examine the effect of FGF proteins to each tissues, the experiment was designed. As FGFs bind to heparin, we used heparin acrylic beads (Sigma-Aldrich, USA) as biomaterials releasing FGFs. Heparin acrylic beads were incubated in FGF9 (CHEMICON, USA), FGF8 (R \&D Systems, UK), or FGF10 (R \&D) proteins (all $50 \mathrm{ng} / \mu \mathrm{l}$ ). Control beads were incubated in bovine serum albumin (BSA, $1 \mu \mathrm{g} / \mu \mathrm{l}$ ). About 100 beads were washed with PBS and soaked in $10 \mu \mathrm{l}$ of growth factor for $45 \mathrm{~min}$ at $37^{\circ} \mathrm{C}$ and then stored at $4{ }^{\circ} \mathrm{C}$.

\section{Organ Culture}

To separate the dental epithelium from the mesenchyme, postnatal day 1 incisors were dissected and incubated with $2 \%$ collagenase at $4^{\circ} \mathrm{C}$ for $3-4 \mathrm{~h}$. Fgf9, Fgf8, and BSA beads were placed on the top of the isolated dental mesenchyme. Fgf10 beads and BSA beads were placed on the apical buds. All explants were cultured on $0.1 \mu \mathrm{m}$ OMNIPORE filters (MILLIPORE, USA) at $37^{\circ} \mathrm{C}$ in a Trowell-type organ culture containing alpha minimum essential medium ( $\alpha$-MEM) supplemented with $10 \%$ fetal calf serum (PAA Laboratories $\mathrm{GmbH}$, Austria) and $1 \%$ penicillin-streptomycin (Gibco, UK). After culturing 24-36 h in vitro, tissues were proceed for Annexin V staining, fixed in 4\% PFA, and processed for whole-mount in situ hybridization analysis.

\section{Annexin V Staining}

Alexa 488-conjugated Annexin V (Molecular Probes, USA) was used to detected apoptotic cells in the tissue cultures. The tissues were incubated with HEPES buffer (10 $\mathrm{mM}$ HEPES, $150 \mathrm{mM} \mathrm{NaCl}, 5 \mathrm{mM} \mathrm{KCl}, 1 \mathrm{mM} \mathrm{MgCl}_{2}$, and $1.8 \mathrm{mM} \mathrm{CaCl}_{2}$ ) containing $1 \mu \mathrm{g} / \mathrm{ml}$ Annexin $\mathrm{V}$-Alexa 488 for $20 \mathrm{~min}$. After rinsing in HEPES buffer, fluorescence was detected using a fluorescence microscope.

\section{In Situ Hybridization and Whole-Mount In Situ Hybridi- zation}

Fgf10 cDNA was a kind gift from H. Ohuchi (University of Tokushima), and Fgf9 cDNA was from M. Abe (Osaka University). Digoxigenin-labeled antisense and sense riboprobes for $F g f 10$ and $F g f 9$ mRNAs were synthesized according to the manufacturer's instructions (Roche Diagnostics $\mathrm{GmbH}$, Switzerland). Lower jaws were fixed in 4\% PFA, embedded in OTC and cryosectioned (10 $\mu \mathrm{m}$ intervals) were hybridized at $60^{\circ} \mathrm{C}$ (Fig. 1A). Processed dental tissues (Fig. 3) were hybridized at $55-57^{\circ} \mathrm{C}$. The probes were detected by an alkaline phosphatase-coupled anti-digoxigenin antibody and NBT/BCIP (Roche) was used as the color substrates.

\section{RESULTS AND DISCUSSION}

\section{Fgfy mRNA and Protein Expression in the Epithelial Tissue in the Apical End of Mouse Incisor}

To search for a candidate that induced or maintained Fgf10, we first examined the expression of mRNAs of several $F g f s$ and $F g f r s$ in the apical bud by RT-PCR. mRNAs of $F g f 1, F g f 8$, and $F g f 9$ were recognized clearly (Fig. 1). PCR products of $F g f r 1 b, F g f r l c, F g f r 2 b$, and $F g f r 2 c$ were also detected (Fig. 1). In these detectable factors, the expression of only Fgf9 mRNA and protein was characteristically observed in the epithelial region adjacent to the mesenchyme 
expressing Fgfl0 mRNA (Fig. 2). In situ hybridization analysis showed that $F g f 9$ mRNA was expressed in the apical bud, IEE (Fig. 2A, arrows), and lingual epithelium (Fig. $\mathbf{2 A}$, large arrow). Fgf9 protein was also strongly detected by immunohistochemistry in the BE and IEE (Fig. 2B, arrows) and weakly in the neighboring mesenchyme. It was not detected in the OEE or differentiated ameloblasts (Fig. 2C-E).

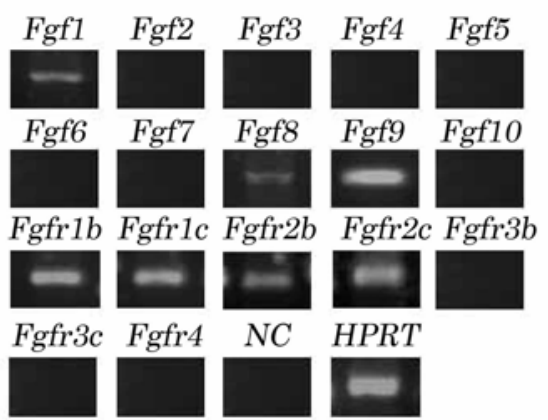

Fig. (1). RT-PCR analysis of $F g f s$ and Fgfrs in the apical bud of mouse incisors.

At neonatal 1day, $F g f 1, F g f 8, F g f 9$ were expressed in the apical bud. Fgfrlb, Fgfrlc, Fgfr $2 b, F g f 2 c$ expression were also detected. Expression of HPRT was used as a positive control and remained constant for each reaction. NC; negative control.

Murine incisors are continuously growing teeth, and all stages of odontogenesis, including amelogenesis and dentinogenesis, can be surveyed if serial sections of the teeth are prepared from the apical end to the incisal edge. The morphological transition of the epithelial-mesenchymal compartment by serial transverse sections of the apical end toward the incisal direction likely reflects the development of the tooth germ in the prenatal stage [8]. In murine molar development, Fgf9 mRNA is expressed in the dental epithelium from E11 to E18 [9]. In particular, it is expressed in the enamel knot as a signaling center that regulates tooth shape at the cap stage and in the IEE at the early bell stage, and is no longer seen in the differentiated ameloblasts of the late bell stage. Fgf9 immunohistochemistry of serial transverse sections showed that in the incisors, Fgf9 expression patterns were very similar to those of the Fgf9 and FgflO mRNA of the developing molar germ (Fig. 2C-F). The expression pattern of FgflO mRNA during molar tooth development is detected faintly around the tooth bud (E13), and continued to express strongly in the dental papilla from cap stage (E14) to bell stage (E16). Though after birth, its expression is slowly decreased [6], and finally disappeared [10].

These results suggested that, as seen in molar development, the expression of Fgflo mRNA was associated with the localization of Fgf9 protein. It is well known that the early developmental process of organogenesis is regulated by several Fgf families of intercellular signaling molecules that are utilized repeatedly at successive stages of development.

\section{Role of Fgf9 in Maintenance of Stem Cell Niche in a Growing Mouse Incisor}

To examine the effects of Fgf9 on the mesenchymal tissues of the apical end, we carried out cell proliferation assays using primary mesenchymal cultures. We found that Fgf9 stimulated proliferation in a dose-dependent manner (Fig. 3A).

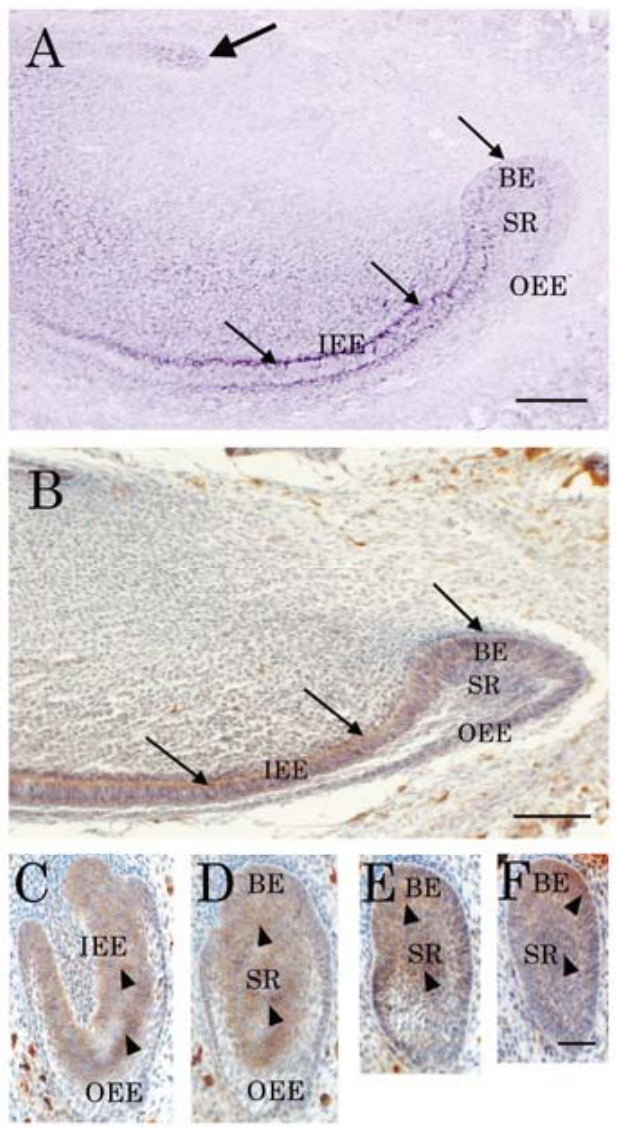

Fig. (2). Localization of $F g f 9$ mRNA and the protein in the apical bud of 1-day-old mice.

(A, B) Sagittal section of a mouse incisor. (A) $F g f 9$ mRNA is seen in the apical bud, IEE (arrows), and lingual epithelium (large arrow). (B) Fgf9 protein is recognized in the BE, IEE, and SR in the apical bud (arrows). It is absent from the OEE and differentiated ameloblasts. (C-F) Transverse section of an apical bud at different positions. Fgf9 protein is expressed in the IEE, which is adjacent to the dental papilla (C, arrowheads). Fgf9 is also expressed in the BE and SR (D-F, arrowheads). BE; basal epithelium, SR; stellate reticulum, IEE; inner enamel epithelium, OEE; outer enamel epithelium. Bars: $50 \mu \mathrm{m}$ (A,B), $25 \mu \mathrm{m}(\mathrm{C}-\mathrm{F})$.

Next, we examined the appearance of apoptotic cells in the presence and/or absence of Fgf9 by Annexin V staining. In the organ cultures with Fgf9-releasing beads, most mesenchymal cells escaped from apoptosis around the Fgf9releasing beads after $24 \mathrm{~h}$ (Fig. 3D). Apoptotic cells were also rarely seen after $48 \mathrm{~h}$ of culture (Fig. $3 \mathbf{H}$ ). In the cultures with BSA beads as a control, most mesenchymal cells reacted with Annexin V after $48 \mathrm{~h}$ (Fig. 3I, arrows).

The survival of mesenchymal cells is reportedly associated with epithelial cells [2]. These results suggested that Fgf9 was expressed in the apical buds, and was a mesenchymal survival/mitogenesis factor.

Furthermore, we examined whether Fgf9 maintains Fgflo expression using an organ culture system of the incisal mesenchyme. The isolated mesenchymal tissues were cul- 
tured in the presence of Fgf9-releasing beads, and the expression of FgflO was analyzed after $24 \mathrm{~h}$ by whole-mount in situ hybridization. Fgflo mRNA was expressed in explants with Fgf9-releasing beads (Fig. 4A, arrows). No expression was detected in the presence of Fgf8- or BSAreleasing beads (Fig. 4B and 4C).
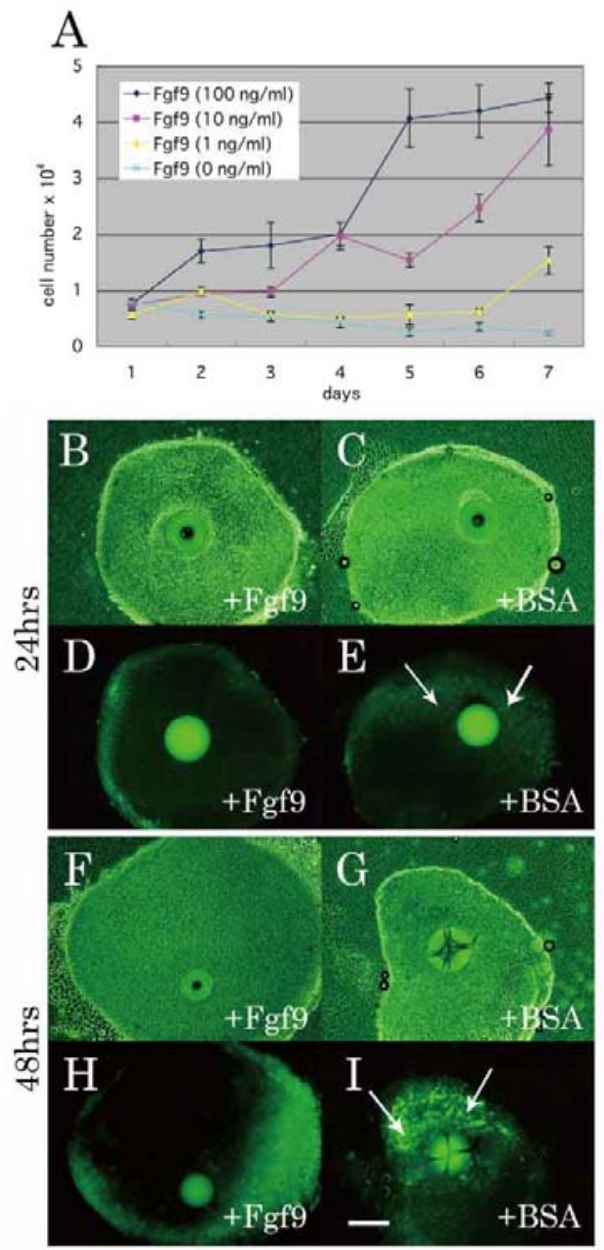

Fig. (3). Effect of Fgf9 on the proliferation and apoptosis of dental mesenchymal cells.

(A) Mesenchymal cells cultured in a medium containing recombinant Fgf9 increased the cell number in a concentration-dependent manner. Data are presented as means $\pm \mathrm{SD}(\mathrm{n}=3)$. (D, E, H, I) Apoptotic cells were stained with Alexa 488-conjugated Annexin V. (B, C, F, G) These pictures were phase contrast images to D, E, $\mathrm{H}$, I respectively. The tissues were cultured with Fgf9-releasing beads for $24 \mathrm{~h}(\mathrm{~B}, \mathrm{D})$ or $48 \mathrm{~h}(\mathrm{~F}, \mathrm{H})$ or with BSA-releasing beads for $24 \mathrm{~h}(\mathrm{C}, \mathrm{E})$ or $48 \mathrm{~h}(\mathrm{G}, \mathrm{I})$. The presence of Fgf9 clearly maintained the cells, and apoptotic cells bound to Annexin V were sparse $(\mathrm{D}, \mathrm{H})$. In the explants cultured with BSA, apoptotic cells began to appear after $24 \mathrm{~h}$ (E, arrows). Those cultured for $48 \mathrm{~h}$ exhibited a larger number of apoptotic cells (I, arrows). Bar, $200 \mu \mathrm{m}$.

These results suggested that Fgf9 is a signaling factor that aids the ability of the apical end mesenchyme to maintain Fgf10 expression. Finally, to examine the effect of Fgf10 on Fgf9 expression in the apical bud, we carried out organ cultures of the buds in the presence and/or absence of Fgf10.

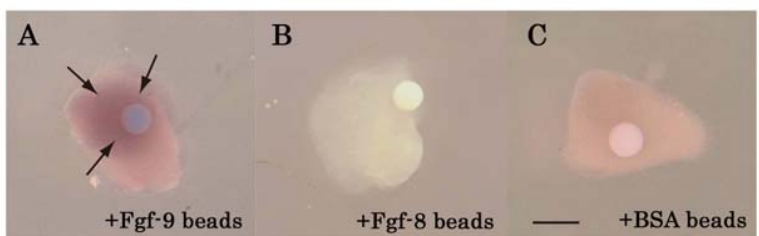

D

E

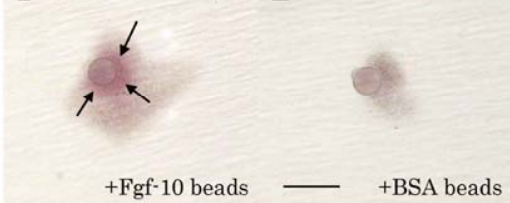

Fig. (4). Effect of Fgf9 on the induction of FgflO mRNA in the dental mesenchyme, and effect of Fgf10 on the induction of Fgf9 mRNA expression in the epithelium.

Stimulation of Fgflo mRNA expression was seen around the Fgf9 beads in the organ culture mesenchyme (A, arrows), but not around the Fgf8 or BSA beads (B, C). Stimulation of Fgf9 mRNA expression is seen around Fgf10 beads in an apical bud (D, arrows). No specific expression is observed around BSA-soaked beads in the apical bud (E). Bar, $200 \mu \mathrm{m}$.

Fgf10-releasing beads maintained $F g f 9$ expression in the apical buds (Fig. 4D, arrows). But in the presence of BSAreleasing beads, the apical buds were destroyed (Fig. 4E). Fgf10 maintained the expression of $F g f 9$ in the apical buds of growing incisors.

The epithelial-mesenchymal interaction is a well-known developmental mechanism. Here, our results suggested that Fgf9 and Fgf10 act as direct regulatory factors for reciprocal interactions and contribute to the maintenance of the stem cell compartment of mouse incisors (Fig. 5). We suggest that the epithelial-mesenchymal interaction is also essential for supporting continuous growth. However, we reported previously that cessation of Fgf10 signaling induces the transition from crown morphogenesis to root formation [11]. At the transitional stage, $F g f 9$ expression also disappears from the dental epithelium [9]. Upstream factors regulating the cessation of the expression of these factors have not yet been elucidated. We suggest that the epithelial-mesenchymal interaction is also essential for supporting continuous growth. Future studies, which should attempt to better understand the

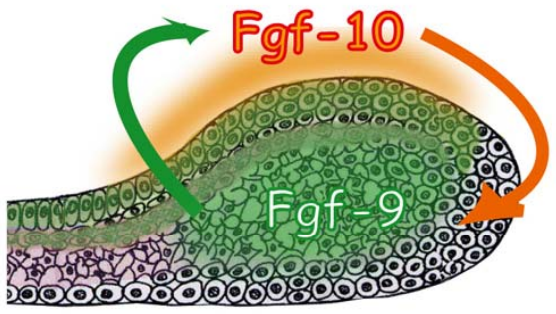

Fig. (5). Maintenance of the dental stem cell niche via Fgf9 and Fgf10 signaling in the growing incisor.

Fgf9 plays a role in the maintenance of $F g f 10$ expression in the mesenchymal cells, whereas Fgf10 stimulates Fgf 9 mRNA expression in the epithelium. The present results lead to the conclusion that the stem cell niche of incisors is formed by the epithelialmesenchymal interaction using the signaling of $F g f 9$ and $F g f 10$. 
molecular mechanisms, will contribute to the development of bioengineered teeth created using human dental epithelial and mesenchymal stem cells.

\section{ACKNOWLEDGEMENT}

This study was supported by KAKENHI (Kiban B, to H.H.) and (Wakate B, to T. Y-T) and Open Research Project in 2007-2011 (to Iwate Medical University) from MEXT, Japan and Iwadare-scholarship 2006, Japan. This research was supported in part by a grant program "Collaborative Development of Innovative Seeds" from the Japan Science and Technology Agency.

\section{REFERENCES}

Harada H, Kettunen P, Jung HS, et al. Localization of putative stem cells in dental epithelium and their association with Notch and Fgf signaling. J Cell Biol 1999; 147: 105-120.

[2] Jernvall J, Thesleff I. Reiterative signaling and patterning during mammalian tooth morphogenesis. Mech Dev 2000; 92: 19-29.

[3] Harada H, Toyono T, Toyoshima K, et al. Fgf10 maintains stem cell compartment in developing mouse incisors. Development 2002; 129: 1533-1541.
[4] Korinek V, Barker N, Moerer P, et al. Depletion of epithelial stemcell compartments in the small intestine of mice lacking Tcf-4. Nat Genet 1998; 193: 79-383.

[5] Gupta R, Fuchs E. Multiple roles for activated LEF/TCF transcription complexes during hair follicle development and differentiation. Development 1999; 126: 4557-4568.

[6] Kettunen P, Laurikkala J, Itaranta P, et al. Associations of Fgf-3 and Fgf-10 with signaling networks regulating tooth morphogenesis. Dev Dyn 2000; 219: 322-332.

[7] Kettunen P, Karavanova I, Thesleff I. Responsiveness of developing dental Tissues to fibroblast growth factors : expression of splicing alternatives of Fgfr1, -2, -3, and of Fgfr4; and stimulation of cell proliferation by Fgf-2, -4, -8 and -9. Dev Genet 1998; 22: $374-$ 385.

[8] Harada H, Ohshima H. New perspectives on tooth development and the dental stem cell niche. Arch Oral Biol 2004; 67: 1-11.

[9] Kettunen P, Thesleff I. Expression and function of FGF-4, -8, and 9 suggest participation in signaling networks regulating morphogenesis and cell differentiation in the developing tooth. Dev Dyn 1998; 211: 256-268.

[10] Tummers M, Thesleff I. Root or crown: a developmental choice orchestrated by the differential regulation of the epithelial stem cell niche in the root of two rodent species. Development 2003; 130: 1049-1057.

[11] Y-Tamaki T, Oshima H, Fujiwara N, et al. Cessation of Fgf10 signaling, resulting in a defective dental epithelial stem cell compartment, leads to the transition from crown to root formation. Development 2006; 133: 1359-1366. 